\title{
Collaboration to Support Rural Student Social-Emotional Needs
}

\author{
Lindsey M. Nichols
}

Anisa N. Goforth

Michaela Sacra

Kaitlyn Ahlers

University of Montana

There is a growing emphasis in U.S. schools to focus on the social-emotional issues of rural students. Specifically, the effect of mental health issues on school success underscores the importance of collaboration between, and among, educators and specialized support personnel (SSP; e.g., school counselors). In rural areas, school counselors and school psychologists are positioned to assist students and their families to provide support within and surrounding the school environment. The purpose of this paper is to: (1) discuss students' social-emotional needs and SSP-educator collaboration in the context of rural schools, and (2) to discuss promising and best practices in collaboration to address students' social-emotional well-being.

Keywords: school counselors, school psychologists, rural, educators

Schools have an increasingly important role in the provision of reliable and consistent socialemotional services for students (Skalski \& Smith, 2006). Approximately $13-20 \%$ of children and adolescents in the United States experience some sort of mental disorder (Merikangas et al., 2010). The high rates of mental health issues have been shown to have significant effects on academic performance, including increases in high school drop-out rates (Cornell, Gregory, Huang, \& Fan, 2013) and declines in overall GPAs and academic engagement (Juvonen, Wang, \& Espinoza, 2011).

The challenges of providing adequate socialemotional supports are especially notable in rural communities. Nearly 8 million people living in rural areas meet the poverty threshold, with approximately $20 \%$ of children in poverty living in rural areas (U.S. Department of Agriculture Economic Research Services [ERS], 2014). Compared to urban children, rural children are also at greater risk for mental health problems and have less access to mental health care (Moore et al., 2005). On the other hand, rural communities are often characterized as small and tight-knit, and rural schools are often a center for community activity, facilitating a sense of connectedness and fostering resiliency in students (Beebe-Frankenberger \& Goforth, 2014).
Rural teachers, administrators, school-based mental health and other support personnel (e.g., speech language pathologists, nurses) have an important role to play in fostering students' resiliency and improving their social-emotional well-being. Collaboration between educators and school-based mental health personnel like school counselors and school psychologists is critical in ensuring that students are receiving social-emotional support to benefit their learning. Although school psychologists and school counselors are conceptualized as educators in schools, for the purposes of this article, we identify "educators" as special and general education teachers and administrators (e.g., principals). Further, in this article we define "specialized support personnel" as school-based mental health professionals (e.g., school psychologists, school counselors) who are school employees and who also play a role in providing social-emotional supports to all students in the school setting. We recognize that many schools have also contracted to work with community based mental health behavior specialists and therapists within the schools, however, that partnership is beyond the scope of this article.

There may be a variety of obstacles that affect SSP and educators' ability to collaborate, including concerns about professional "turf," lack of 
knowledge about the skills and competencies each professional has to contribute, limited time and resources, and consultation guidelines (Choi, Whitney, Korcuska, \& Proctor, 2008). The purpose of this paper is to 1) discuss students' socialemotional needs and SSP-educator collaboration in the context of rural schools, and 2) to discuss best practices in collaboration to address students' socialemotional well-being.

\section{Students' Social-Emotional Needs}

Schools have become an important resource and provider in student mental health, especially given the rise of mental health issues among students. In fact, nearly 70 to $80 \%$ of youth who receive mental health services do so in the education context (Farmer, Burns, Phillips, Angold, \& Costello, 2003). A 2013 Center for Disease Control report indicated that the most prevalent mental health disorders were Attention-deficit/Hyperactivity Disorder, depression, and conduct-related disorders (Perou et al., 2013). These rates of mental disorders are particularly concerning when considering that the report also indicated that suicide was the second leading cause of death among adolescents aged 12-17 years in 2010 . It is clear that a high number of students in our schools are experiencing mental health problems and more resources are warranted.

Students in rural communities experience somewhat higher rates of mental health problems compared to their counterparts in other communities (Lenardson, Ziller, Lambert, Race, \& Yousefian, 2010); however, rural children have less access to mental health care (Howell \& McFeeters, 2008). Mental health stigma is also a significant concern for rural families. In fact, individuals who live in rural areas are less likely to seek health care, often due to fear of prejudice or community rejection (Murimi \& Harpel, 2010). Further, children in rural areas experience higher rates of poverty (U.S. Department of Agriculture, 2013), which places these children at significantly greater risk of direct exposure to violence at school (Carlson, 2006).

Schools can play an important role in addressing students' mental health to support educational outcomes. Research has suggested that mental health issues early in life (e.g., aggression, internalizing symptoms) are associated with increased risk for poor academic achievement (Masten et al., 2005; Valdez, Lamber, \& Lalongo, 2011). However, if mental health issues are addressed early in life through interventions, children are more likely to improve both mental health symptoms and academic achievement (Becker, Brandt, Stephan \& Chorpita, 2013). In fact, school-based mental health programs in rural schools have shown to improve students' mental health symptoms and academic performance (Michael et al., 2013). Overall, addressing students' mental health can have longterm implications for their well-being in both school and in life.

\section{SSP Collaboration with Rural Educators}

Specialized support personnel (SSP), such as school counselors and school psychologists, play an important role in providing academic and mental health support to students in rural schools. Generally, school counselors identify their roles in schools as serving the academic (e.g., study skills, planning), career (e.g., development, exploration), and socialemotional (e.g., bullying, grief and loss) needs of all students (ASCA, 2012; 2014). School counselors address each area using data-driven preventative and reactive services such as assessing school climate, classroom guidance, group and individual counseling, and crisis response. Similarly, school psychologists have an important role in the provision of services to students and their families. School psychologists provide data-based decisions through direct and indirect service delivery to students, families, and schools (NASP, 2010). School psychologists provide consultation (e.g., classroom management), assessment, and interventions for academic skills and mental health. Along with school counselors they also focus on school-wide practices to promote learning and family-school collaboration services.

The shared interest in students' socialemotional well-being aligns educators, school counselors and school psychologists; however, there are a number of challenges associated with how these professional roles are utilized in rural communities. First, one of the significant challenges that SSP experience is related to which professional is responsible for what aspect of mental health services. That is, there may be "turf wars" among support professionals and educators about who provides assessment and interventions to students in the school. School counselors and school psychologists have similar goals in supporting students' social and emotional well-being; however, there may be difficulties in deciding what services are provided by which professional. 
This role confusion may be particularly enhanced in some rural schools that contract from outside behavioral therapists or specialists. These mental health professionals, not school personnel, may be tasked to conduct some, or perhaps even most, of the direct service with primarily high-need students (Butts, Casey, \& Ewen, 2014). These practitioners may pose challenges for school's SSP because SSP may find themselves further from the direct counseling or intervention roles that they had originally envisioned as part of their daily responsibilities. Indeed, studies have found that the limited collaboration that occurs between specialized professionals may be enhanced if roles are more clearly delineated (Choi et al., 2008).

There are also additional challenges for school counselors and school psychologists in rural schools, particularly related to establishing connections and collaborations. In general, school counselors report that collaboration with other school professionals is relatively frequent and includes various stakeholders, including school psychologists (Gibbons, Diambra, \& Buchanan, 2010); however, these collaborations were not defined as an "easy or smooth task" (p. 19). In particular, collaboration is difficult in schools where distance and schedules limit or prevent interaction. For example, when school counselors have rotating schedules across multiple schools, they may not have the opportunity to be physically present in the building at the same time to collaborate with education teams. The resulting limited interaction can decrease the ability for school counselors to clarify their roles and develop systemic guidelines to facilitate better communication with each other and the school staff (Choi et al., 2008).

Relatedly, rural school districts often contract through educational co-operatives because they are unable to afford a full or part-time school psychologist. As a result, school psychologists may have multiple schools, requiring them to primarily focus their services on assessment rather than intervention, and reducing the likelihood of establishing strong relationships with the students, parents or teachers at their schools. Consequently, many students in rural schools lack access to their school psychologist compared to those in suburban or urban schools.

Additionally, the yearly fluctuation of resources based on school budgets, such as personnel, socialemotional curricula, technology, and materials, may pressure all school professionals to take on multiple roles. Educators and support personnel may not be able to collaborate effectively without the opportunity to discuss the social-emotional needs of students in the school, define expectations and roles within social-emotional services, or clarify ways to support each others' roles, while clarifying ways to access the various services.

A final challenge that can complicate the alliance between educators and SSP is the stigma associated with mental health. In general, there are perceptions that individuals with mental health problems are dangerous or that children's mental health problems are attributed to lack of appropriate parenting (Parcesepe \& Cabassa, 2013). This stigma is particularly pronounced in rural communities, which are often characterized as being tight-knit (Wagenfeld, 2003). Adults in isolated rural areas report more stigma associated with seeking help for mental health problems compared to adults in other geographic areas (Stewart, Jameson, \& Curtin, 2015). This stigma is particularly difficult because of the presence of "stigma by association" among families with children with emotional or behavioral problems (Heflingre, Walson, Mukolo, \& Brannan, 2014). That is, families perceived that teachers and other community members viewed them in a more negative light (e.g., that their children were not as smart as other children). Families may not want to be seen entering a community mental health agency or have other community members know that their child is receiving services from a school counselor or school psychologist. In a qualitative study, Sutton \& Pearson (2002) found that one of the primary challenges school counselors encountered in rural and small town culture was "a tendency to see such social problems as substance abuse, family deterioration, and crime as something that exist 'out there, but not here in our quiet town'" (p. 270). Rural families may not perceive a problem exists, and in turn, not seek mental health services in schools.

Overall, SSP like school counselors and school psychologists have an important role in supporting students' social-emotional well-being in rural schools to benefit their learning and well-being. Despite the barriers that exist, such as challenges in professional responsibilities, mental health stigma, and fluctuation in school budgets and resources, school counselors and school psychologists are aligned in their shared interest in students' mental health and find ideal ways to address the need working in conjunction with their school colleagues. 


\section{Best Practices in Collaboration to Address Students' Social-Emotional Well-being}

Supporting students in rural schools to achieve their best requires collaboration between educators and SSP. Efficient and deliberate collaboration between school counselors and school psychologists is imperative because of their specialized training in student mental health (Zambrano, Castro-Villarreal, \& Sullivan, 2012). In fact, professional standards of ASCA (2012) and NASP (2010) delineate the importance of collaboration within schools and across communities to support the achievement of students. However, without the alliance with the other school educators with their own knowledge and skills, the maximum benefits of any supports to students are lost. In the following section, we summarize specific, research-based practices related to collaboration between and across student support personnel and educators to address students' socialemotional needs. In particular, we highlight some specific examples of how schools in Montana, a rural state, have utilized these approaches to benefit students' social-emotional well-being.

\section{Educator Training on Mental Health}

An important first step in supporting the socialemotional well-being of rural students is increasing educators' knowledge about students' mental health. Research studies have shown that one important factor that influenced teachers' readiness to assist students with mental health problems was their ability to understand their students' issues (Sisask et al., 2014). Furthermore, teachers and administrators received little, if any, training related to preventing or intervening for students with mental health concerns (Koller \& Bertel, 2006). Consequently, teachers often feel underprepared to support student's socialemotional well-being (Reinke, Stormont, Herman, Puri, \& Goel, 2011).

Teachers and administrators are often the first line of defense of students experiencing social, emotional, and behavior concerns, and although there may be an SSP in the school, teachers are more likely to encounter the day-to-day issues of their students. Programs such as Parents and Teachers as Allies (NAMI), Youth Mental Health First Aid (National Council for Behavioral Health), and Mental Health Facilitation, Educator's Edition (MHF-EE; NBCC-I, 2014), can be springboards for discussion and skills to support students' mental health in the teacher role.
Depending on the program, educators learn how to communicate more effectively with students to support the student's mental health and understand how to use the resources available in school to best meet the student's needs.

In Montana, MHF-EE has been implemented to meet the needs of rural educators. As a state, we have one of the highest suicide rates in the nation (Montana Department of Public Health \& Human Services, 2016), yet a significant lack of resources. Rural educators noted that mental health is a stigmatized topic in their communities and they experienced challenges with how to support their students (Nichols, Goforth, Borntrager, Ahlers \& Giuliani, 2014). The MHF-EE program was adapted from the original MHF training developed by NBCCInternational, a division of the National Board for Certified Counselors, in response to foreign countries seeking a training for community members to become better informed helpers in addressing mental health needs. Educators attending that training found the information helpful, but not specific enough to the school context. Therefore, MHF-EE specifically focuses on preparing educators to be helpful in a wide range of difficult situations with a multicultural and multidisciplinary focus. Using lecture, discussion, and role play educators review 20 modules or topical areas on such areas as: understanding student's feelings; recognizing stress, distress, and disorder; communicating in MHF (e.g., types of questions, reflection, active listening); working with child maltreatment; and making referrals and consulting with helping professionals.

Consequently, after participating in the 30 -hour MHF-EE program, rural educators felt empowered within their roles to better address student social and emotional needs. For example, teachers reported that reinforcement of basic communication skills was helpful in their professional and personal interactions (Nichols et al., 2014). Through the MHF-EE program, they learned ways to listen to their students and rephrase questions, which subsequently allowed them to de-escalate challenging situations. With these skills and perspectives, teachers expressed more confidence in seeking additional, appropriate resources for support.

Providing access to informational and skill programs like MHF-EE, SSP could collaborate with other educators in the school to create an opportunity for consultation on specific mental health topics and communication skills, while also collaborating to reduce stigma and empower all educators within their 
role. Collaboration could also include resource mapping (see the National Center on Secondary Education and Transition, 2005) to partner and collaborate with other helpful resources, in consultation with their SSP, such as Job Corps, local faith-based organizations, and various non-profits serving children and families including reliable online resources such as the Collaborative for Academic, Emotional, and Social Learning (CASEL) across levels.

\section{Multi-tiered Systems of Support}

SSP and educators could work together to enhance students' learning and social-emotional wellbeing through Multi-tiered Systems of Support (MTSS). MTSS is defined as a multi-tiered system of service delivery to promote the use of high quality, evidence-based instruction and behavioral supports (Horner, Sugai, \& Anderson, 2010). Students have access to services at the universal, secondary and tertiary level depending on the student's needs. Weist, Grady Ambrose, and Lewis (2006) lend more support for the development of student support teams to navigate MTSS to bring all important stakeholders to the table to implement culturally relevant interventions. We will specifically discuss professional learning communities (PLCs) later on, and first explore how SSP and educators systematically collaborate on each tier level to address students' academic success and socialemotional well-being.

The U.S. Department of Education's Office of Special Education's (OSEP) Technical Assistance Center, developed Positive Behavioral Interventions and Supports (PBIS), which is under the umbrella of MTSS. The Montana Office of Public Instruction (OPI) implements their own specialized version, called the Montana Behavior Initiative (MBI) to support students' social-emotional well-being. SSP and educators can collaborate in obtaining the requisite "buy-in" from key stakeholders, such as teachers and parents, to promote the integration of a social-emotional focus into rural schools. Further, researchers have established that interventions must be acceptable (i.e., viewed as fair, reasonable, appropriate, and consistent with stakeholders' expectations) to be implemented; therefore, SSP can assist in selecting and modifying a social-emotional learning program that fits the local context (Huddleston, 2013; Meyers, Tobin, Huber, Conway, $\&$ Shelvin, 2015). SSP may interview various stakeholders to identify specific problems that need to be addressed and to adapt to fit the needs of the school and larger community (Meyers et al., 2015).

At the Tier 1 or universal level, all students in a school are screened for social, emotional, or behavior concerns. Educators and SSP can collaborate on administering a brief mental health screener (e.g., Behavior and Emotional Screening System-Third Edition; Kamphaus \& Reynolds, 2015) to be able to find students who may be at risk for social, emotional, or behavior concerns. Screening may be particularly important in rural schools where there is a lack of access to mental health resources and where there is likely stigma associated with mental health. Moreover, all teachers in general education classrooms could administer the screener, which would reduce the stigma associated with screening. The SSP could support the teachers through training of how to administer the screeners and how to use data from those screeners to determine those at risk for social and emotional issues.

An example of a universal, research-based intervention that facilitates prevention of socialemotional issues is Second Step: A Violence

Prevention Program (Committee for Children, 2002). Research shows that this intervention is effective in improving social-emotional skills and reducing disruptive behavior in elementary students (Low, Cook, Smolkowski, \& Buntain-Ricklefs, 2015). Furthermore, although SSP sometimes deliver the social-emotional learning curricula themselves, given the time constraints they often face working in rural schools, SSP can serve as trainers and consultants for educators to facilitate the implementation of a socialemotional curriculum in their own classrooms (Meyers et al., 2015). SSP can train educators to deliver the intervention as intended and can provide additional support by checking in with educators (Sanetti \& Collier-Meek, 2015). SSP may provide treatment integrity support depending on the level of support required by educators. For instance, SSP can provide direct training to all implementers of the intervention and then, if data indicates the need for additional support, SSP may offer additional consultation via group meetings, direct observation, modeling, or other strategies (Sanetti \& CollierMeek, 2015).

At the Tier II level, SSP and educators can work together to determine whether certain students would benefit from additional supports. Grade-level teams could meet to examine the screening data and educators can refer students who may be at risk. 
Further, educators may recommend that a particular student receive additional support from SSP given the day-to-day changes that students often experience. For instance, if a student experiences a difficult loss of a family member, educators are frequently the first to notice long-lasting changes in their students. Therefore, educators can collaborate with SSP to enroll the student in a weekly group on grief. In addition to working together to determine which students would benefit from additional supports, SSP are most commonly the providers of small-group interventions, such as a group on grief, social skills groups, or groups to support students who identify as a sexual and/or gender minority. Other interventions showing positive impacts like Check-in/Check-out (CICO; Mitchell, Adamson, \& McKenna, 2016) are important for educators and SSP to consider in their consultation. See PBIS World at http://www.pbisworld.com/ for additional information.

For students who are not responsive to Tier I or Tier II interventions, more intensive individualized intervention may be provided at the Tier III level. Educators and SSP can continue to work together to determine whether particular students would benefit from an even more individualized level of support. SSP typically provide the Tier III services through meeting individually with students, or SSP may assist the student and their family in obtaining individualized support within the community. Importantly, SSP can collaborate with educators to engage in a bidirectional information sharing process. For instance, SSP can provide information regarding the symptoms the students might display and how the student's diagnosis and associated symptoms might affect the child's functioning at school (Yosai, Rose Baker, Ahlers, \& Goforth, 2016). In turn, educators can keep SSP informed regarding important emotional, social, or behavioral changes. Further, SSP can collaborate with educators to provide updates on the skills the student is learning or to implement interventions in the classroom that will be helpful to the student. Specifically, a student's classroom teacher can provide specific praise or encouragement to a student for using a relaxation/coping skill learned with SSP (e.g., breathing techniques, asking for a break) in the classroom. In addition, educators and SSP can work together to utilize needed interventions in the classroom (e.g., assistance in setting up a visual schedule, training on how to deliver time out for aggressive behavior).

\section{Effectively Utilizing SSP in Schools}

The function and responsibilities of specialized support personnel can vary greatly from school to school. As a result, professional roles of these personnel can be unknown or unclear to the educators, or even to those SSP themselves. Many school counselors and school psychologists continue to advocate for their defined professional roles at a local and state level using national professional organization standards. Regardless of the data to support these models, local decisions on how to manage and fill student support personnel time typically takes precedent. Administrators and other staff must learn about the roles of school counselors and school psychologists so they can make the most informed decision on how best to utilize the knowledge and skills of these professionals. Similarly, SSP must also learn more about the roles and responsibilities of the educators in the school. Few states require teaching to become a school counselor or school psychologist and while many have teaching or other experience in schools, the unique dynamics in each district, school, and classroom needs to be understood and respected by outsiders looking to provide support.

SSP could attend or present at conferences of the other education professionals, particularly within the state (e.g., the school counselor attends the state education conference). In Montana, there is a large, annual conference held in the fall, the MEA-MFT Educators Conference. The conference is held at a different city each year and is a major event for continuing education. The state's school counseling association hosts their own track of educational sessions focused on a broad array of topics, which all educators are welcomed to attend. Face-to-face meetings through conferences like these may be especially helpful in rural states where there may be few numbers of these professionals and may facilitate stronger connections or even partnerships through the academic year.

Additionally, and related to earlier discussion of MTSS, SSP are also creating professional learning communities (PLC; DuFour, DuFour, \& Eaker, 2009) in districts or regional areas to learn more about how professional roles function from school-to-school as well as to discuss opportunities for collaboration with educators across levels. The purposefulness of PLCs rather than "just another meeting" focuses on 10 critical questions DuFour (2007, p. 5) details that collectively guide the team to identify common goals 
for students and data driven assessment of the PLC efforts as well as students' performance. These questions include:

1. Are we clear on the knowledge, skills, and dispositions each student is to acquire as a result of this course, grade level, and unit we are about to teach?

2. Have we agreed on the criteria we will use in assessing the quality of student work, and can we apply the criteria consistently?

3. Have we developed common formative assessments to monitor each student's learning on a timely basis?

4. Do we use the formative assessments to identify students who are having difficulty in their learning so that we can provide those students with timely, systematic interventions that guarantee them additional time and support for learning until they have become proficient?

5. Do we use data to assess our individual and collective effectiveness? Do assessment results help us learn from one another in ways that positively affect our classroom practice?

6. Does our team work interdependently to achieve SMART goals that are Strategic, Measurable, Attainable, Results-oriented, and Time-bound?

7. Are continuous improvement processes built into our routine work practice?

8. Do we make decisions by building shared knowledge regarding best practices rather than simply pooling opinions?

9. Do we demonstrate, through our collective efforts, our determination to help all students learn at high levels?

10. Do we use our collaborative team time to focus on these critical issues?

Although shifting some of the language of these questions, such as "course" to "intervention" to better relate to social-emotional learning programming this best practice provides important structure for educators and SSP working together. Along these lines, SSP should also make efforts to describe and define support roles to educators at school staff or level meetings to create awareness and clarification. Although access to face-to-face events can be challenging, online opportunities to connect have also been growing to learn more about the roles and resources SSP can provide. In addition to national and state professional organization websites to gain clarity, the Montana OPI offers the Comprehensive System of Personnel Development (CSPD) online. Training content vary throughout the year and each year, but it provides a platform to exchange information and ideas across professional content areas including keeping educators informed of support services available to them. For example, a monthly podcast was offered on a range of topics school counselors frequently cope with (e.g., suicidality, cutting, homelessness). Experts provided information along with a question and answer session that allowed access to all educators to learn more while getting insight into the range of topics SSP cope with in their work and, therefore, could be a resource for educators. The key to all of these strategies is the openness and action to seize the opportunity to learn from each other and how to be most effective to serve students.

\section{Conclusion}

There is a clear need to support the increasing numbers of students in the U.S. experiencing socialemotional issues in school. Although data on mental health is continuing to grow, more research is needed to know particularly how school personnel are making a difference in schools located in rural communities. The lack of resources for mental health in these communities highlights the importance of effective and deliberate collaboration between educators and specialized support personnel.

Additionally, the collaboration of other mental health providers within the school or in the community needs to be further developed. Although we discussed the confusion and sometimes overlap in roles between school counselors and school psychologists, particularly in rural communities, many states also employ school social workers as well as private mental health organizations to provide more intensive individual therapy through clinical mental health counselors or social workers. The additional supports could create more robust mental health teams; however, they can also facilitate challenges in communication, collaboration, or cohesion between and among mental health professionals.

Regardless of what professionals a school retains, the need for collaboration with educators is highlighted again and again. Although isolated geographically, rural and Native American communities have rich and complex traditions and cultures. Educators and mental health support 
personnel hold a professional responsibility to work together as they become members of those communities to support the needs of students - despite the challenges everyone faces, it takes a collaborative village to raise a healthy child.

\section{References}

American Counseling Association. (2014). ASCA mindsets \& behaviors for student success: $K-12$ college- and career-readiness standards for every student. Retrieved on November 28, 2016 from https://schoolcounselor.org/asca/media/asca/ho me/MindsetsBehaviors.pdf

American School Counseling Association. (2012). The ASCA national model: A framework for school counseling. Alexandria, VA: Author.

Becker, K. D., Brandt, N. E., Stephan, S. H., \& Chorpita, B. F. (2013). A review of educational outcomes in the children's mental health treatment literature. Advances in School Mental Health Promotion, 7, 1-4.

Beebe-Frankenberger, M. \& Goforth, A. N. (2014). Best practices in school psychological practice in rural settings. In A. Thomas \& P. Harrison (Eds.), Best Practices in School Psychology: Foundations (Vol. VI). Bethesda, MD: National Association of School Psychologists.

Butts, E., Casey, S., \& Ewen, C. (2014). Advancing school mental health in Montana: Partnership, research, and policy. In M. D. Weist, N. A. Lever, C. P. Bradshaw, \& J. S. Owens (Eds.), Handbook of school mental health: Research, training, practice, and policy (75-86). New York: Springer US.

CASEL. (n.d.). Collaborative for academic, social, and emotional learning. Retrieved from http://www.casel.org/

Carlson, K. T. (2006). Poverty and youth violence exposure: Experiences in rural communities. Children \& Schools, 28(2), 87-96. doi:http://dx.doi.org/10.1093/cs/28.2.87

Choi, H., Whitney, Y., Korcuska, S., \& Proctor, T. (2008). Consultation practices between school counselors and school psychologists: Implications for training and practice. Journal of Applied School Psychology, 24(2), 303-318.

Committee for Children. (2012). Second step: A violence prevention program curriculum grades 4-5 teacher's guide (3 ed.). Seattle, WA: author.

Cornell, D., Gregory, A., Huang, F., \& Fan, X. (2013). Perceived prevalence of bullying and teasing predicts high school dropout rates. Journal of Educational Psychology, 105, 138-149.

DuFour, R. (2007). Professional learning communities: A bandwagon, an idea worth consider, or our best hope for high levels of learning? Middle School Journal, 39, 4-8.

DuFour, R., DuFour, R., \& Eaker, B. (2009). New insights into professional learning communities at work. The challenge of change: Start school improvement now, 2, 87-103.

Farmer, E. M. Z., Burns, B. J., Phillips, S. D., Angold, A., \& Costello, E. J. (2003). Pathways into and through mental health services for children and adolescents. Psychiatric Services, 54(1), 60-66. doi:10.1176/appi.ps.54.1.60

Gibbons, M. M., Diambra, J. F., \& Buchanan, D. K. (2010). School counselor perceptions and attitudes about collaboration. Journal of School Counseling, 8(34), 1-28.

Heflinger, C. A., Wallston, K. A., Mukolo, A., \& Brannan, A. M. (2014). Perceived stigma toward children with emotional and behavioral problems and their families: The Attitudes about Child Mental Health Questionnaire (ACMHQ). Journal of Rural Mental Health, 38, 9-19. doi: http://dx.doi.org/10.1037/rmh0000010

Howell, E., \& McFeeters, J. (2008). Children's mental health care: Differences by race/ethnicity in urban/rural areas. Journal of Health Care for the Poor and Underserved, 19, 237-247. doi: 10.1353/hpu.2008.0008

Horner, R. H., Sugai, G., \& Anderson, C. M. (2010). Examining the evidence base for school-wide positive behavior support. Focus on Exceptional Children, 42, 1-14.

Huddleston, L. (2013). Evaluating treatment acceptability, treatment integrity, and cultural modifications of a bullying prevention intervention. Available from PsycINFO. (1492675898; 2013-99231-121).

Juvonen, J., Wang, Y., \& Espinoza, G. (2011). Bullying experiences and compromised academic performance across middle school 
grades. The Journal of Early Adolescence, 31, 152-173. doi:10.1177/0272431610379415

Reynolds, C. R., \& Kamphaus, R. W. (2015). BASC3 Behavioral and Emotional Screening Systems. http://www.pearsonclinical.com/education/prod ucts/100001402/behavior-assessment-systemfor-children-third-edition-basc-3.html

Koller, J. R., \& Bertel, J. M. (2006). Responding to today's mental health needs of children, families and schools: Revisiting the preservice training and preparation of school-based personnel.

Education \& Treatment of Children, 29(2), 197217.

Lenardson, J. D., Ziller, E. C., Lambert, D., Race, M. M., \& Yousefian, A. (2010). Access to mental health services and family impact of rural children with mental health problems. University of Southern Maine Muskie School of Public Service: Main Rural Health Research Center.

Low, S., Cook, C. R., Smolkowski, K., \& BuntainRicklefs, J. (2015). Promoting social-emotional competence: An evaluation of the elementary version of Second Step ${ }^{\circledR}$. Journal of School Psychology, 53, 463-477. doi: http://dx.doi.org/10.1016/j.jsp.2015.09.002

Masten, A. S., Roisman, G. I., Long, J. D., Burt, K. B., Obradović, J., Riley, J. R.et al. (2005).

Developmental cascades: Linking academic achievement and externalizing and internalizing symptoms over 20 years. Developmental Psychology, 41, 733-746.

Merikangas, K. R., He, J. P., Brody, D., Fisher, P. W., Bourdon, K., \& Koretz, D. S. (2010). Prevalence and treatment of mental disorders among US children in the 2001-2004 NHANES. Pediatrics, 125, 75-81. doi: 10.1542/peds.2008-2598

Meyers, A. B., Tobin, R. M., Huber, B. J., Conway, D. E., \& Shelvin, K. H. (2015). Interdisciplinary collaboration supporting social-emotional learning in rural school systems. Journal of Educational \& Psychological Consultation, 25(2-3), 109-128. doi:10.1080/10474412.2014.929956

Michael, K. D., Albright, A., Jameson, J. P., Sale, R., Massey, C., Kirk, A.et al. (2013). Does cognitive behavioural therapy in the context of a rural school mental health programme have an impact on academic outcomes? Advances in School Mental Health Promotion, 6, 247-262. doi: 10.1080/1754730X.2013.832006
Montana Department of Public Health \& Human Services. (2016). Montana 2016 suicide mortality review team report. Retrieved from http://www.sprc.org/sites/default/files/resourceprogram $/ 2016 \% 20$ Montana $\% 20$ Suicide $\% 20 \mathrm{Mo}$ rtality\%20Review\%20Report.pdf

Moore, C. G., Mink, M., Probst, J. C., Tompkins, M., Johson, A., \& Hughley, S. (2005). Mental health risk factors, unmet needs, and provider availability for rural children: South Carolina Rural Health Research Center.

Mitchell, B. S., Adamson, R., \& McKenna, J. W. (2016). Curbing our enthusiasm: An analysis of the check-in/check-out literature using the Council for Exceptional Children's evidencebased practice standards. Behavior Modification, 1- 25. doi: $10.1177 / 0145445516675273$

Murimi, M. W., \& Harpel, T. (2010). Practicing preventive health: The underlying culture among low-income rural populations. The Journal of Rural Health,26(3), 273-282. doi:http://dx.doi.org.weblib.lib.umt.edu:8080/1 0.1111/j.1748-0361.2010.00289.x

National Association of School Psychologists. (2010). Model for comprehensive and integrated school psychological services, NASP practice model overview. In National Association of School Psychologists (Ed). Bethesda, MD: National Association of School Psychologists.

National Center on Secondary Education and Transition. (2005). Essential tools: Community resource mapping. Retrieved from http://www.ncset.org/publications/essentialtools /mapping/

National Council for Behavioral Health. (n.d.). Youth Mental Health First Aid. Retrieved from http://www.mentalhealthfirstaid.org/cs/take-acourse/course-types/youth

NBCC-International. (2014). Mental Health Facilitation. Retrieved from http://www.mentalhealthfacilitator.com/Progra $\underline{\mathrm{m}}$

Nichols, L. M., Goforth, A. N., Borntrager, C., Ahlers, K., \& Giuliani, M., (2014, September 19). Improving teacher's understanding of children's mental health for academic success. Annual Conference on Advancing School Mental Health in Pittsburg, PA. 
Parcesepe, A. M. \& Cabassa, L. J. (2013). Public stigma of mental illness in the United States: A systematic literature review. Administration and Policy in Mental Health and Mental Health Services Research, 40, 384-399. doi:10.1007/s10488-012-0430-z

Perou R, Bitsko RH, Blumberg SJ, Pastor P, Ghandour RM, Gfroerer JC, et al. (2013). Mental health surveillance among children-United States 2005-2011, from http://www.cdc.gov/mmwr/preview/mmwrhtml/ su6202a1.htm?s_cid=su6202a1_w

PBIS World. (n.d.). Retrieved from http://www.pbisworld.com/

Reinke, W. M., Stormont, M., Herman, K. C., Puri, R., \& Goel, N. (2011). Supporting children's mental health in schools: Teacher perceptions of needs, roles, and barriers. School Psychology Quarterly, 26(1), 1-13. doi:10.1037/a0022714

Sanetti, L. M. H., \& Collier-Meek, M. A. (2015). Data-driven delivery of implementation supports in a multi-tiered framework: A pilot study. Psychology in the Schools, 52(8), 815828. doi:10.1002/pits.21861

Sisask, M., Värnik, P., Värnik, A., Apter, A., Balazs, J., Balint, M.et al. (2014). Teacher satisfaction with school and psychological well-being affects their readiness to help children with mental health problems. Health Education Journal, 73, 382-393. doi: 10.1177/0017896913485742

Skalski, A. K. \& Smith, M. J. (2006). Responding to the mental health needs of students. NASPOnline. Retrieved from http://www.nasponline.org/resources/principals/ Scohol Based Mental Health Services.pdf

Stewart, H., Jameson, J. P., \& Curtin, L. (2015). The relationship between stigma and self-reported willingness to use mental health services among rural and urban older adults. Psychological Services. doi:10.1037/a0038651

Sutton, J. M. \& Pearson, R. (2002). The practice of school counseling in rural and small town schools. Professional School Counseling, 5, 266-276.

U. S. Department of Agriculture Economic Research Service. (2014). Rural poverty and well-being. Retrieved from http://www.ers.usda.gov/topics/rural-economypopulation/rural-poverty-well-being/povertyoverview.aspx

U.S. Department of Agriculture. (2013). Report on the definition of "rural". Washington, D.C.: U.S. Department of Agriculture.

U. S. Office of Special Education Programs. (2015). Positive Behavioral Interventions \& Supports. Retrieved from https://www.pbis.org/

Valdez, C. R., Lambert, S. F., \& Ialongo, N. S. (2011). Identifying patterns of early risk for mental health and academic problems in adolescence: A longitudinal study of urban youth. Child Psychiatry \& Human Development, 42, 521-538. doi:10.1007/s10578-011-0230-9

Wagenfeld, M. O. (2003). A snapshot of rural and frontier America. In B. H. Stamm (Ed.), Rural behavioral health care: An interdisciplinary guide (pp. 33-40). Washington, D.C.: American Psychological Association.

Weist, M. D., Grady Ambrose, M., \& Lewis, C. P. (2006). Expanded school mental health: A collaborative community-school example. Children \& Schools, 28, 45-50.

Yosai, E.R., Ahlers, K., Rose Baker, M., \& Goforth, A.N. (2016). The special education process: A primer for psychologists outside of school settings. The Montana Psychologist.

Zambrano, E., Castro-Villarreal, F., \& Sullivan, J. R. (2012). School counselors and school psychologists: Partners in collaboration for student success within RTI and CDCGP frameworks. Journal of School Counseling, 10(24). Retrieved from http://www.jsc.montana.edu/articles/v10n24.pdf

\section{About the authors:}

Dr. Lindsey Nichols is an Assistant Professor of Counselor Education at the University of Montana - Missoula. She is a licensed school counselor and Licensed Clinical Professional Counselor in Montana. Her research interests include counseling preparation, practice, and research, as well as cultural approaches to health and wellness.

Dr. Goforth is an Assistant Professor of Psychology and Director of the School Psychology Graduate Training Programs in the Department of Psychology at the University of Montana. Her primary research is related to serving 
the needs of children from culturally and linguistically diverse backgrounds and cultural competence of school psychologists.

Ms. Michaela Sacra is a Counselor Education and Supervision doctoral student at the University of Montana. Her primary research interests include school counseling supervision and culturally appropriate internationalization of the counseling profession.

Kaitlyn Ahlers is a doctoral student in Clinical Psychology at the University of Montana. Her primary research interests include the effects of living with a chronic condition on the mental health of children and adolescents and the dissemination and implementation of evidence-based practices for youth mental health. 